\title{
Towards an Animal Ethics for the Anthropocene ${ }^{1}$
}

\section{Jozef Keulartz}

\begin{abstract}
The complex problems of wildlife conservation during the current stage of the Anthropocene - the 'Great Acceleration' - are forcing us to develop an alternative to the traditional (utilitarian und deontological) approaches within animal ethics. I will put forward Martha Nussbaum's capability approach as a promising alternative to these traditional approaches, with the proviso that the current version of her list of basic animal capabilities will need to undergo some revision.
\end{abstract}

"A dog has the right to be a dog."

Article 12 of the Constitution of the Republic of Užupis

\section{Introduction}

Today, the animal world is under increasing pressure, given the magnitude of anthropogenic environmental stress, especially from climate change and habitat fragmentation. Climate change facilitates the introduction, establishment, and spread of invasive species at the expense of native species. It also confronts native species with the alternative to move outside their historic ranges or to go extinct - to 'move it or lose it' (Minteer \& Collins 2010). Managed relocation may be required when threatened species are not able to move on their own to other regions where conditions are more suitable. Relocated animals will have to go through a long process, from capture and captivity to transport and release to novel areas.

Habitat fragmentation leads to the ongoing conversion of what were originally continuous populations to so-called 'metapopulations': collections of subpopulations, that are spread geographically over patches of habitat. Because these patches are usually small and because the movement of the animals between these patches is restricted for lack of connectivity, local extinctions of subpopulations are a common event. This situation asks for metapopulation management. Central to this type of management is the exchange of animals

\footnotetext{
1 This chapter was first presented at the Human Development \& Capability Association Conference in Washington, September 10-13, 2015, in a session with Martha and Rachel Nussbaum, Amy Linch and Jeremy Benedik-Keymer. It was published in Bernice Bovenkerk and Jozef Keulartz. 2016. 'Animal Ethics in the Age of Humans' (pp. 243-264). Cham, Switzerland: Springer.
} 
between in situ populations (in the wild) and ex situ populations (in captivity). On the one hand, captive populations can be used for restocking in areas with declining populations or for reintroduction in areas where populations have gone extinct; on the other hand, the demographic and genetic viability of ex situ populations can be boosted by supplying genetic founders from wildlife populations.

As a result of these global environmental changes, the distinction between in situ and ex situ conservation is gradually breaking down. Instead of a stark contrast between the wild and the walled, we now encounter a continuum of environments more or less impacted by human activity. Animals are becoming increasingly dependent on care in conditions of temporary or permanent captivity. In this situation, we need to develop an alternative to the existing leading accounts of animal ethics: the utilitarian (animal welfare) approach and the deontological (animal rights) approach. The main problem with these traditional approaches is that they offer no guidelines at all for a morally sound management of wild animals in captivity.

Here, I will put forward Martha Nussbaum’s capabilities approach as a promising alternative to the traditional animal welfare and animal rights approaches. According to this approach, the welfare of animals must be measured against the possibilities an environment offers animals to actually display their basic natural capabilities. If appropriate care is given, animals can flourish in less natural and more human environments.

To answer the question what actually is involved in appropriate care, i.e. care that allows animals to employ their natural capabilities, I will make a distinction between three types of care: care for the environment (habitat) of animals, species-specific care, and individual care. I will argue that the moral adequacy of various human-animal practices depends on whether they succeed in achieving a balanced mix of these types of care. I will show how the balance will gradually shift if we move across the continuum between wild and captive contexts: in protected nature areas the weight is on care for the habitat of animals, in zoos the weight is on species-specific care, while performing animals will predominantly depend on individual care (Keulartz and Swart 2012).

But first, I will briefly discuss the pros and cons of Nussbaum's capabilities approach vis-à-vis utilitarianism and the rights theory. Although I am convinced that Nussbaum's approach offers a favorable alternative to these approaches, I nonetheless feel that there are some contradicting treads running through her account. I will therefore sometimes have to think 'with Nussbaum against Nussbaum'. 


\section{The Pros and Cons of Nussbaum's Capabilities Approach}

According to Clare Palmer (2010) the three most important approaches to animal ethics - the utilitarian approach, the rights approach, and the capabilities approach, are 'capacity oriented'. All these approaches argue that animals that possess certain keystone capacities, such as sentience, self-consciousness, or rationality, are morally considerable and are therefore entitled to respectful treatment. Palmer points out that, in the case of utilitarianism and the rights theory, this capacity orientation takes the form of a 'class system'. The members of a group of animals with similar keystone capacities deserve equal moral consideration, regardless of their species (Palmer 2010, 45-46). For Tom Regan, who is well known for his animal rights theory, this class includes all mentally normal adult mammals over the age of roughly one year, that can be considered 'experiencing subjects-of-a-life', while utilitarian philosopher Peter Singer assumes an even broader class of animals that are entitled to equal moral consideration, namely all sentient beings with a capacity for suffering. ${ }^{2}$

The problem with this view on the classification of animals manifest in utilitarianism and rights theories is that it is too general to provide for sufficient guidance in shaping morally sound human-animal relationships. Rights theories are even less able to give such guidance because they are almost exclusively concerned with negative duties, i.e., duties not to act, and to abstain from certain kinds of actions, such as harming, killing, interfering, infringing on liberty et cetera. Most work on animal rights are of little or no help in dealing with captive animals because it only tells us what we should not to do to animals (Palmer 2014, 707).

Although the capabilities approach is also capacity oriented, it differs from the utilitarian approach and the rights approach in one very important respect. Nussbaum rejects the view, taken by both these approaches, that species membership itself is of no ethical and political significance at all. Following James Rachels, Nussbaum calls this view 'moral individualism' ${ }^{3}$ The capabilities approach, by contrast, does in fact attach moral significance to species membership as such (Nussbaum 2006, 362/3). It is based on a species-specific norm of flourishing, that tells us what the appropriate benchmark is for judging whether a member of a species has decent opportunities for flourishing, and that commits us to bring

\footnotetext{
2 "No matter what the nature of the being, the principle of equality requires that its suffering be counted equally with the like suffering - insofar as rough comparisons can be made - of any other being” (Singer 1975, 8).

${ }^{3}$ According to Rachels, "moral individualism is a thesis about the justification of judgments concerning how individuals may be treated. The basic idea is that how an individual may be treated is determined, not by considering his group memberships, but by considering his own particular characteristics” (Rachels 1990, 173).
} 
members of that species up to that norm (idem, 365). What is important for Nussbaum is the fulfillment of species-specific capabilities, where each living being flourishes as the sort of being it is.

The main advantage of Nussbaum's species-specific norm compared to moral individualism and the associated class system is that it can provide more and better guidance to professionals and practitioners working in various human-animal practices. The capabilities approach has more concrete guidelines to offer than utilitarianism and rights theories. And whereas rights theories stress negative duties and tell us above all what we should not do to animals, the capabilities approach has a strong affirmative character. According to Nussbaum, we have a positive duty to support the capabilities of all morally considerable beings, up to some minimum threshold level specific to each species. Utilitarian approaches are less negative than rights theories, but they are usually also less affirmative than the capabilities approach. This also applies to Singer's preference utilitarianism. By focusing on the passive state of preference satisfaction, Nussbaum explains, "utilitarianism shows a deficient regard for agency. Contentment is not the only thing that matters in human life; active striving matters, too" (idem, 73; 283). The capabilities approach places great emphasis on activity and flourishing. "Its basic goal is to address the need for a rich plurality of life activities" (idem, 346).

However, the considerable conceptual gains that Nussbaum is able to achieve through the introduction of the species-specific norm of flourishing in animal ethics are at least partly being undone by the way she compiles a catalogue of innate or 'basic' capabilities relevant to animal species. On the one hand, Nussbaum's account of animal capabilities seems to be distinctly pluralist. The capabilities approach is attentive to the fact that each species has a different form of life, and is capable of recognizing a wide range of types of animal dignity, and of the corresponding needs for flourishing (idem, 327). But on the other hand, Nussbaum suggests a one-fits-all approach, that has a distinct anthropocentric character as it applies the same human yardstick to all animal species. ${ }^{4}$ Although she fully acknowledges that speciesspecific entitlements of animals are based upon their various characteristic forms of life and flourishing, she nonetheless wants to use the existing list of human core capabilities "to map

\footnotetext{
${ }^{4}$ In Women and Human Development, Nussbaum argues that the central capabilities "are held to have value in themselves, in making the life that includes them fully human" (emphasis added) (2000, 74).
} 
out, in a highly tentative and general way, some basic political principles that can guide law and public policy in dealing with animals” (idem, 392). ${ }^{5}$

\section{The Predator Problem}

What seems most problematic, when applied to animals, is the Other Species capability, i.e. the capability or entitlement to be able to live with concern for and in relation to animals, plants, and the world of nature (Cripps 2010, 8). This capability, Nussbaum suggests, “calls for the gradual formation of an interdependent world in which all species will enjoy cooperative and mutually supportive relations with one another. Nature is not that way and never has been. So it calls, in a very general way, for the gradual supplanting of the natural by the just” (2006, 399). This clearly implies that we should stop all predators from hunting and eating prey. ${ }^{6}$

Like animal ethicists of all colors, Nussbaum is also struggling with the so-called 'predator problem'. This problem arises from the need to reconcile two seemingly conflicting views. On the one hand, most animal ethicists believe that, if animals truly have a right to life, then we ought to protect them from being killed by their predators. But, on the other hand, they generally agree that there is a basic presumption against interference with animals in the wild (Cowen 2003).

Peter Singer, for instance, fears that interfering with nature to save animals from predation would cause more harm than good. ${ }^{7}$ However, as a matter of principle, Singer believes that "if, in some way, we could be reasonably certain that interfering with wildlife in a particular way would, in the long run, greatly reduce the amount of killing and suffering in the animal world, it would, I think, be right to interfere” (Singer 1973). ${ }^{8}$

Tom Regan is also opposed to interference with nature to protect prey animals. Although wild animals can certainly harm one another, Regan argues, they cannot violate one

\footnotetext{
${ }^{5}$ In her review of Steven Wise's book Rattling the Cage, Nussbaum points to an important difference in the ethical evaluation that is involved in preparing capabilities lists: "With the human capabilities, we are evaluating ourselves. If we get it wrong, we are the ones who take the consequences. With animals, we are again the ones performing the evaluation - and there is great danger that we will get it wrong” (Nussbaum 2001, 1542/3). ${ }^{6}$ This demand calls to mind the utopian conditions after the Second Coming of Christ, where 'The wolf shall dwell with the lamb’ (Wissenburg 2011).

${ }^{7}$ Saving wild animals “on any large scale would have disastrous ecological consequences”, according to his fellow-consequentialist Aaron Simmons (2009, 26).

${ }^{8}$ White's Professor of Moral Philosophy Jeff McMahan (2010) has embraced "the heretical conclusion that we have reason to desire the extinction of all carnivorous species". He is actually in favor of selecting carnivorous species for extinction and herbivorous species for survival, and would also support using genetic modification to gradually turn carnivorous species into herbivorous ones.
} 
another's rights since, in contrast to human predators, nonhuman predators are not moral agents, but only moral patients. "Animals are not moral agents and so can have none of the same duties moral agents have, including the duty to respect the rights of other animals" (Regan 1983, 357).

Interestingly enough, in the preface of the second edition of The Case for Animal Rights, Regan has put forward an idea that might shed new light on the predation problem. In response to Carl Cohen's critical question, why we should save a human life from predators but not an animal's life when doing so would be equally within our power (Cohen 1997, 95), Regan asks us to imagine two cases: one in which a wild animal is threatened by a predator and another case in which the predator is threatening a human child. He argues that the difference between the two cases is that wild animals possess a certain 'competence' and are capable of 'using their natural abilities' to survive on their own in the wild, whereas human children do not. We honor this competence of wild animals by just letting them be, even if their lives are threatened by predators (Regan 1983, xxxvi-xxxviii).

This recourse to the notion of competence with regard to prey animals could open the way for a less ambivalent solution to the predator problem than we have seen to date. This solution would in fact be perfectly in line with the capabilities approach, that centers on the idea that a creature's well-being is dependent on its opportunities to realize some basic natural abilities. But this avenue is blocked as long as we include the Other Species capability, that calls for cooperative and mutually supportive relations between species, in the list of central capabilities. As Nussbaum has argued, however, this list is “open-ended and humble” and “can always be contested and remade” (Nussbaum 2000, 77). It is, therefore, always possible for items to be both added to or deleted from the list. In the next section, it will be shown that, without a revision of the current version of the list, the capabilities approach runs into some substantial trouble when it comes to the management of wilderness areas.

\section{Wilderness Areas and the Care for Habitat}

Like most animal ethicists, Nussbaum attaches moral weight to the possibility for animals to enjoy sovereignty. She endorses "the idea that species autonomy is part of the good for nonhuman animals” (Nussbaum 2006, 375). At first glance, she seems to endorse the view that animals can pursue their own flourishing best when left to their own devices, and that we have no positive duties to support their welfare, providing them with food, shelter and healthcare. Such a 'benevolent despotism' of humans over animals might even be perceived 
as morally repugnant, because part of what it is to flourish for animals "is to settle certain very important matters on its own, without human intervention, even of a benevolent sort” (idem, 373).

On closer inspection, however, Nussbaum does not fully accept the view that we have no positive duties towards animals in the wild, although she admits that there is "much truth" in this view. The reason is that in today's world it is hardly the case anymore for animals to live sovereign and autonomous lives, unaffected by human interference. The environments on which animals depend for their survival are being increasingly disturbed or destroyed by human activity, and their opportunities for nutrition, shelter, and free movement are in constant decline. In this situation, where the possibilities for flourishing are severely limited, Nussbaum believes that we should not leave the animals to their fate but should take measures to preserve “at least some part of the creature’s original habitat” (idem, 376).

Since wild animals are currently under increasing pressure from human activity, Nussbaum clearly assumes that we have a positive duty of care for their habitat. However, living in the early stages of what has been called the planet's 'sixth mass extinction', care for the habitat of wild animals cannot rely merely on preservation and protection. The rate and magnitude of the anthropogenically driven 'defaunation', asks for more offensive and interventionist strategies such as recreation, restoration and rewilding (Seddon et al. 2014).

On both sides of the Atlantic, such strategies are directed at the enlargement of nature areas, their connection into coherent and comprehensive networks that allow the exchange of individuals between populations, and, last but not least, the (re)introduction of keystone species i.e. those species whose impact on their environment is disproportionately large relative to their numerical abundance - their return is vital for the restoration of the evolutionary and ecological potential that was lost with their removal (Keulartz 2016).

In North America, most emphasis is on the restoration of large carnivores, because of their role in the top-down regulation of ecosystems. Large predators occupy the highest trophic level and create impacts that ripple downward along the trophic ladder. They activate trophic cascades that are essential to the preservation of biodiversity and the maintenance of ecosystem integrity. A famous case in point concerns the reintroduction of the grey wolf in Yellowstone National Park in 1995. With the return of the wolf the elk herd, one of the world's largest elk herds, declined $40 \%$ in five years. The wolves prevented elk from 
overbrowsing willow and aspen near rivers and streams, and this gave rise to a substantial rebound of the beaver, itself a keystone species that may increase species diversity et cetera. ${ }^{9}$

Most animal ethicists will oppose the (re)introduction of predators. Although they are not in favor of interfering with nature on behalf of prey animals, they are even less inclined to intervene at their expense. Rights theorists, for instance, will argue that by (re)introducing predators, humans will become implicated in the killing of prey animals, and because, unlike predators, humans are moral agents, we have to do with a rights violation in this case (Milburn 2015). ${ }^{10}$

Nussbaum is also opposed to the introduction of 'natural predators' to control animal populations. She prefers any non-violent method of population control to such a violent method. The 'painless predation' of animals through human hunting, she argues, may be an alternative to "other deaths that elks would die, such as starving or being torn apart by wolves” (Nussbaum 2006, 394). In an interview with Carla Faralli, Nussbaum puts it this way:

"Sometimes people think that they have done a great good thing if they make hunting illegal and then, when the deer are reproducing too rapidly and can't find enough to eat, they introduce wolves to tear the deer apart. Actually, I am sure that for the deer the hunter’s gun is better than the wolves’ jaws, more sudden and less excruciating” (Nussbaum and Faralli 2007, 158)

However, "painless predation” is a misleading term for human hunting. Hunters will in fact have to shoot far more prey animals than the numbers that predators would be able to kill. This is because prey populations are controlled not only top-down by predation but also bottom-up by food availability. Such a bottom-up approach, in which the system is regulated by energy moving upward from lower to higher trophic levels, i.e., from plants to herbivores to carnivores, is prevalent in Europe. Here, most emphasis is on the restoration of wild large herbivores and the introduction of naturalistic grazing, a policy that has been initiated by the management of the Oostvaardersplassen, a Dutch polder situated five meters below sea level and just half an hour from Amsterdam. Apart from red deer, roe deer, wild boar, and wisent,

\footnotetext{
${ }^{9}$ Recently, some doubts have been raised regarding this success story (Mech 2012).

${ }^{10}$ According to Dale Jamieson, moral evaluation is clearly in order when "predation is in some way affected by human agency, either because we have structured the encounter or because the predator is under our direct or indirect control” (Jamieson 2008, 186/7).
} 
European rewilders also use proxies for large ungulates that went extinct, such as the aurochs and the tarpan (the European wild horse) (Klaver et al. 2002).

As a consequence of the resource-driven bottom-up approach, the population size of large herbivores in the Oostvaardersplassen and similar reserves is regulated by limited food availability. Consequently, it is not allowed in these reserves to prevent starvation, either by proactive culling or by supplementary feeding. ${ }^{11}$ Only reactive culling to prevent unnecessary and prolonged suffering of moribund animals is allowed.

It is important to realize that the top-down regulation by predation and the bottom-up regulation by food availability are forces working together simultaneously (Miller et al. 2001). The relative influence of these forces varies among ecosystems and depends on a range of variables, such as rainfall patterns, soil fertility, and especially the body size and diversity of predators and prey in the system, as can be illustrated by the graph below about the Serengeti (Hopcraft et al. 2009, 122). Here, large herbivores, such as elephant, tend to be regulated by food abundance (dashed blue line), whereas smaller herbivores, such as wildebeest, are regulated by food quality (dotted green line). Only the smallest herbivores, such as oribi, are mainly predator regulated (solid red line).

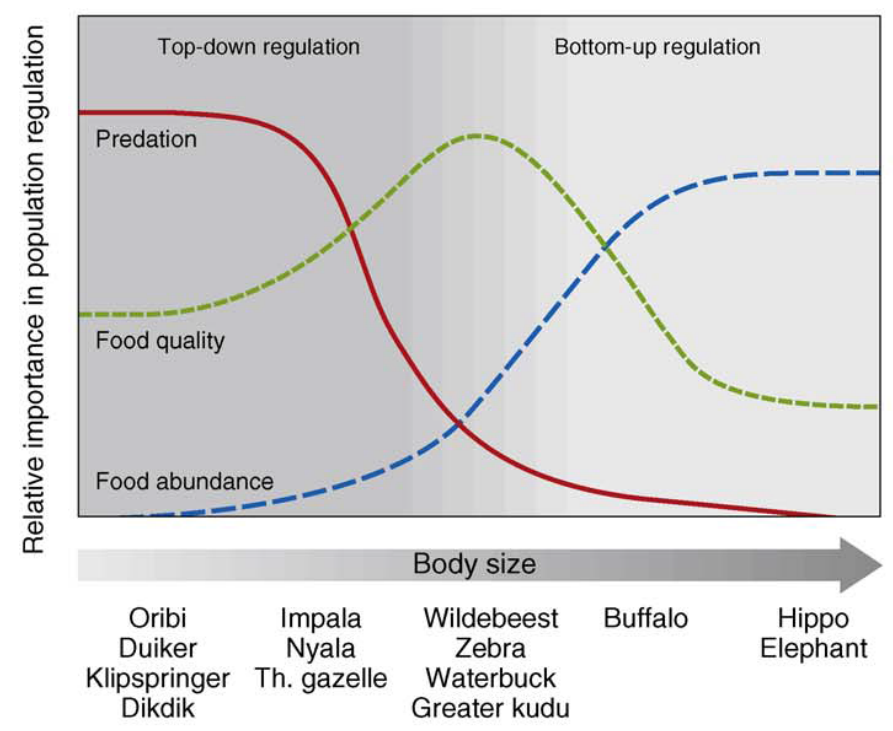

In short, populations are in varying combinations regulated top-down by predation and bottom-up by food availability. ${ }^{12}$ Because hunters have to substitute for both top-down and bottom-up control of prey populations in order to prevent starvation, they generally have to

\footnotetext{
${ }^{11}$ Gary Varner (1995) has termed this type of culling 'therapeutic hunting'.

${ }^{12}$ In higher latitudes with ecosystems with only one major predator and a few prey species, such as tundra, desert, boreal and temperate woodlands, bottom-up control of prey is, in fact, dominant.
} 
shoot very large numbers. For instance, in the Veluwe, with 90,000 hectare one of the Netherlands' largest nature reserves, 60 percent of the red deer and 80 percent of the wild boar are shot annually. It is estimated that you need 1,400 wolves during 8 months to realize such a large-scale cull.

This type of 'fauna management' has a disastrous impact on the natural mechanisms that animals in the wild have developed to cope with periodic food shortages. Red deer, for instance, are able to resort to a strategy of what has been called 'hidden hibernation'; their heart rate goes down to 30 beats per minute, and their energy use decreases to 13 percent of the annual average (Arnold et al. 2004). Another coping mechanism concerns the reduced fertility of female animals due to severe weight loss. They skip giving birth for one and sometimes even two years, which will offer them the opportunity to regain strength. A perverse effect of large-scale culling is the artificial increase of the reproduction rate of the animals. Red deer in the Veluwe produce up to three times more calves than in the Oostvaardersplassen, where they are only subject to reactive instead of proactive culling.

So, it is highly questionable whether "for the deer the hunter's gun is better than the wolves' jaws”, as Nussbaum has claimed in the interview with Carla Faralli - human predation seems far from being a worthwhile substitute for natural predation. Abolishing or inhibiting natural predation, is problematic, if only because a fairly large number of animals are both predator and prey. But, more importantly, it is problematic because it would definitely make an end to species sovereignty and autonomy, and have a negative impact on the flourishing, not only of predator species but also of prey species.

Nussbaum points out the danger "of romanticizing nature, or suggesting that things are in order as they are, if only we humans should stop interfering” (Nussbaum 2006, 367). But she runs the risk of falling into the other extreme, by demonizing nature. Following John Stuart Mill in his essay 'Nature', she portrays predators as vicious criminals, merciless executioners and great monsters, inflicting painful torture and gruesome death on other vulnerable and defenseless creatures. This picture is deceptive because the hunter's gun is seldom more sudden and excruciating than the wolves' jaws; quick kills are rare, and many animals suffer prolonged, painful deaths when hunters severely injure but fail to kill them. ${ }^{13}$ On the other hand, a prey animal that is being chased by a predator will produce endorphin, a chemical that is kin to opiates, and that acts as an analgesic, a natural pain-killer.

\footnotetext{
${ }^{13}$ A British study of deer hunting found that 11 percent of deer killed by hunters died only after being shot two or more times and that some wounded deer suffered for more than 15 minutes before dying (Bradshaw and Bateson 2000).
} 
But, above all, Nussbaum's picture is a caricature of both predators and prey, who have evolved over many millennia in interaction with each other. During this tight evolutionary relationship, prey species have developed a stunning array of mechanisms to cope with predators for every stage of their struggle: the avoidance of detection by the predator (such as camouflage, refuge use, nocturnality), the avoidance of attack once detected (mimicking animals with strong defenses, signaling to the predator that pursuit is not worthwhile), the avoidance of capture once attacked (fleeing, bluffing strength), and the avoidance of consumption once captured (playing death or 'thanatosis', sacrificing body parts or 'autotomy').

In a certain sense, one can say that predators and prey fit together like puzzle pieces. Without predators, prey animal's possibilities for flourishing will be diminished, because all the amazing capabilities they have gained over evolutionary time to cope with predators might be rendered meaningless. All in all, we can safely conclude that it is counterproductive to extent the Other Species capability to the animal kingdom. Instead of working to ensure that all species will enjoy cooperative and mutually supportive relations, we should respect the natural capabilities of animals, be they predator or prey, without romanticizing or demonizing their agonistic interactions. ${ }^{14}$

\section{Zoos and Species-Specific Care}

Given the global processes mentioned in our introduction, traditional in situ (place-based) conservation methods seem no longer sufficient to save threatened species (Sandler 2012). The magnitude of anthropogenic environmental stress from bioinvasion, habitat fragmentation, nitrogen deposition, biodiversity loss, and, above all, climate change, makes it unavoidable to replace the hands-off approach that has guided mainstream species conservation until recently by a more proactive and interventionist strategy. However, this new strategy has led to manifold conflicts between wildlife conservationists and animal protectionists (Minteer \& Collins 2013).

\footnotetext{
${ }^{14}$ David Schlosberg has also rejected Nussbaum's idea that we should protect prey animals from predators. He contends that she has a too narrow view of what it means to flourish as a prey animal: "we need to understand and accept that part of the flourishing of animals is to be the protein for other life forms... To be food for others is the essence of functioning for some beings" (Schlosberg 2007, 151). Elizabeth Cripps has rightly remarked that this specific argument is only convincing, so long as it concerns the species as a whole. "It may be part of the functioning of the species that it is food for another species; but to say that it is part of the functioning of that particular gazelle to be so overlooks precisely the concern for the capacity of individual animal lives to go better or worse that Nussbaum wants to recognize” (Cripps 2010, 10).
} 
Animal ethicists generally question the intentions of conservationists. For instance, Dale Jamieson is convinced that the motivation for reintroduction and rewilding programs “centres on the satisfaction of human preferences rather than on concerns about animal welfare or the maintenance of ecological values" (Jamieson 2008, 194). He shares the view of Marc Bekoff (2000) that these programs are nothing but humans' attempts to 'redecorate' nature. Conservationists, for their part, are strongly opposed to animal rights proponents in particular. According to Michael Hutchins, "it is time to face up to the fact that animal rights and conservation are inherently incompatible and that one cannot be an animal rights proponent and a conservationist simultaneously” (Hutchins 2008, 816).

As Hutchins rightly points out, animal rights proponents have fought vehemently against virtually every form of wildlife research or management. They oppose programs to control or eliminate destructive invasive species that involve techniques such as hunting and trapping or make use of pesticides such as piscicides, chemical substances which are poisonous to fish (Keulartz and Van der Weele 2008). They also oppose managed relocation, because of the chronic stress that relocated animals will experience at all stages of the process, from capture and captivity to transport and release to novel areas. And, last but not least, they oppose ex situ conservation through zoos and aquaria.

As a response to the ongoing decline in effectiveness of in situ conservation and the accompanying loss of biodiversity, zoos began to turn their attention to the conservation of endangered species and wildlife in the 1970s and 1980s. ‘Captivity for Conservation’ became a crucial slogan for the modern zoo. A major milestone in this development was the Convention on Biodiversity which was signed at the Earth Summit in Rio de Janeiro in 1992. In the wake of the Earth Summit the first World Zoo Conservation Strategy was launched in 1993. Its conclusion explicitly stated that, at a time when species, habitats and ecosystems worldwide are threatened with extinction, modern zoos must commit to the conservation of species and wildlife.

Most animal rights proponents consider infringing an individual's right to freedom for the sake of the preservation of the species as morally wrong. For Regan any type of captivity or manipulation of a sentient animal is morally unacceptable, irrespective of the possibly beneficial consequences for the protection of rare or endangered species. The rights view's answer to the question whether zoos are morally defensible, "not surprisingly, is No, they are not” (Regan 1995, 46). Utilitarian Peter Singer, on the other hand, seems to accept some reductions in animal welfare when the survival of entire populations or species is at stake. He feels, however, that most zoos today fail to live up to their conservation mission. They tend to 
confine animals for our amusement in ways that are contrary to their interests. Even if these zoos do occasionally preserve an endangered species, "what is the point of preserving animals if they are having miserable lives?” ${ }^{15}$ His fellow-utilitarian Jamieson is even more skeptical about zoos than Singer; he considers the benefit of species conservation "not significant enough to overcome the presumption against depriving an animal of its liberty” (Jamieson 1995, 60).

The problem with the rights approach and the utilitarian approach is that they say little or nothing to guide us in the case of animals that depend on care in conditions of temporary or permanent captivity. As we have seen, these approaches hold the view that species membership in itself is of no moral relevance; they do not recognize significant differences within the broad group of animals that belong to the class that deserve equal moral consideration because they possess some core capacities, such as sentience or being an experiencing subject-of-a-life. Nussbaum’s capabilities approach, by contrast, does attach moral significance to the species to which a creature belongs. Her species-specific account of flourishing commits care takers to support the capabilities of captive animals, and enables us to judge whether they have ample and appropriate options and opportunities to perform species-specific activities.

Compared to utilitarians and rights proponents, Nussbaum has a rather positive opinion about zoos. With respect to endangered species, she argues that we should not only try to preserve at least some part of their original habitat, but that we should also make "intelligent and careful” use of zoos. "Many animals will do better in an imaginative and well-maintained zoo than in the wild, at least in present conditions of threat and scarcity" (Nussbaum 2006, 376). In the interview with Carla Faralli, Nussbaum expresses her belief "that zoos have a good role to play, both in educating the public about animals and in developing breeding programs. The new type of zoo is a place not for painful captivity but for wide-ranging movement, and these zoos are sites of important research” (Nussbaum and Faralli 2007, 160).

There are, however, limitations to the extent to which species-specific activities can be carried out in zoos. It may be true that there is a strong tendency toward the 'naturalization' of zoos, but this process runs up against limits. Zoos cannot include the reproduction of natural contingencies. Some forms of predatory behavior, such as chasing and killing prey, cannot

\footnotetext{
${ }^{15}$ http://www.mkhumanists.org.uk/node/73.
} 
realistically be simulated in captivity. Likewise, in the absence of predators, some forms of prey behavior, such as vigilance, may not be exhibited at appropriate levels in captivity.

In short, captivity usually deprives wild animals of the necessity and opportunity to pursue the tasks of survival, such as finding food and avoiding enemies. Heini Hediger, know as the 'father of zoo biology', considered this lack of occupation of the captive animal as "one of the most urgent problems in the biology of zoological gardens” (Hediger 1950, 158). Quite a lot of studies show that animals prefer to work for their food, rather than to be fed ad libitum; they will most often voluntarily work for their food, even if the same food is available free (Neuringer, 1969; Anderson \& Chamove, 1984; Laule and Desmond 1998). Especially mammals are unsuited to an existence in which no effort on their part is required to meet their basic needs (Kreger et al. 1998).

A solution to this problem is 'substitution.' Animals, particularly mammals, are flexible enough to modify their behavior to suit a wide range of situations and to substitute one form of action for another depending on the facilities available. In Frontiers of Justice, Nussbaum mentions an example of substitution. Modern zoos have to face the problem of allowing the capabilities of predatory animals like tigers to be exercised without actually harming or killing prey animals. The Bronx Zoo has found an answer to this questioninstead of giving a tiger a tender gazelle to crunch on, it gives the tiger a large ball on a rope, whose resistance and weight symbolize the gazelle. "Wherever predatory animals are living under direct support and control," Nussbaum concludes, “these solutions seem the most ethically sound” (Nussbaum 2006, 370). ${ }^{16}$

The introduction of such novel objects - 'toys and treats' - is just one option for providing 'environmental enrichment,' by which the expression and development of speciesspecific behaviors and abilities can be achieved, usually to the benefit of animal welfare. Feeding enrichment is also an important option. Anna Claxton (2011) mentions three strategies in feeding enrichment: increasing the number of daily feeding sessions; making the feeding schedule less predictable; and making the food less easy to obtain, either by hiding it or by adding a level of complexity to the food manipulation process, such as providing live prey or full carcass meals (see also Ross 2002).

Another major enrichment strategy concerns the improvement of enclosure design. Most zoos suffer from a severe lack of space; the space for all the zoo animals in the world could easily fit within New York’s 212.7 km² borough of Brooklyn (Conway 2011, 4). To

\footnotetext{
${ }^{16}$ Nussbaum notes with some regret that "we do not have the option of giving the tiger in the wild a nice ball on a string to play with” (Nussbaum 2006, 379).
} 
address this problem, zoos have a number of options. They can reduce the number of species they maintain that are not threatened and specialize in species that are. They can also replace big charismatic mammals with smaller species, particularly amphibians, invertebrates and some species of fish, which occupy less space, are relatively inexpensive to keep, have a high birth rate and are easy to reintroduce (Keulartz 2015; in this volume).

A recent and also very promising strategy to tackle the problem of limited space concerns the creation of walkways between enclosures that allow animals greater freedom of movement. Building a network of trails, in particular top tree trails, gives animals the opportunity to rotate between various interconnected display and off-display areas. Animals may spend mornings in one area and afternoons in another. The concept of such animal rotation displays is based on Hediger's theory of territory, a wild animal's living space made up of a variety of special areas, such as dens, basking sites, and foraging areas, interconnected by regular pathways (Coe 2004).

Still other methods of environmental enrichment for captive animals include sensory stimulation in the form of auditory, olfactory and visual cues, and social enrichment, which provides animals the opportunity to interact with other animals, either conspecifics (same species) or contraspecifics (other species). A good example of the latter are mixed-species exhibits. They provide an interactive and dynamic experience for the animals, visitors and zoo staff. In mixed-species enclosures activity levels are typically higher, with more play behaviors, and this generally has a positive effect on both the physical and the mental health of the animals (Veasey and Hammer 2010, 151). Moreover, interspecific interactions can contribute to successful reintroductions. Animals from mixed-species exhibits are more likely to cope with the complexity of their natural habitat after introduction. Even 'negative' interspecific interactions, e.g. controlled nonlethal exposure to predators, may be beneficial in survival postrelease (idem, 153).

Finally, a special case of environmental enrichment concerns what Hediger has called 'occupational therapy'. “The captive animal,” Hediger suggested, “must be given a new interest in life, an adequate substitute for the chief occupation of freedom... This substitute can take the form of biologically suitable training and assumes the importance of occupational therapy” (Hediger 1950, 158).

Animal training is an important component of animal enrichment programs as it facilitates exercise and mental stimulation. Training can also provide the animals with the motivation, skill, and confidence they need to use the enrichment devices they have been offered in the most successful way. Through training by positive reinforcement, animals can 
be taught to participate in daily health and husbandry care, without sedation or restraint. By voluntarily participating in their treatment during dental work, blood draws, urine collection, stethoscope examinations, artificial inseminations et cetera, they will obtain benefits in the form of preventive and curative health care. Also, the stress that is usually related to these procedures can be significantly reduced by teaching animals to voluntarily participate in their daily health and husbandry care.

Furthermore, training is also relevant for the relationship between the animal and its care giver, which is of critical importance for many species in captivity. The well-being of zoo animals is greatly enhanced if there is a trusting, amiable relationship with their keepers. The trust between animals and keepers can be reinforced by training animals to follow commands and teaching them simple routines using positive reinforcement. "Building a trusting and caring relationship, teaching the different procedures on cue and establishing strong reinforcement histories with our animals, enabling them to behave in a secure manner and provide the ability to anticipate what is happening to them, whether good or bad” (Brando 2010, 783).

Although training undoubtedly improves the welfare of animals and also makes routine examination and veterinary treatment less stressful, zoos are reluctant to use training, as Trevor Poole has noticed, "because they fear to be accused of not being serious or of turning into circuses” (Poole 1998, 91). For years animal training was motivated by the entertainment industry and has been associated only with animal shows.

\section{Performing Animals and Individual Care}

The circus has witnessed a transition from the use of punishment and other coercive methods to the use of methods that focus on positive reinforcement, which provides animals greater choices and greater control over their lives. The circus has also increasingly moved away from showing costumed animals displaying human-like characters toward showcasing them performing more naturalistic behaviors. Both developments are captured in the Code of Conduct for Animals by the European Circus Association (ESA 2007): “All animal training must be based on operant conditioning and the use of positive reinforcement and repetition of desired behaviors. Training should showcase individual animals’ natural behaviors and athletics.” These developments didn’t prevent campaigns against the use of wild animals in circus acts to be successful in achieving bans almost worldwide. Nussbaum (2006, 392) seems to be quite positive about this development, although her capability approach does not 
preclude acceptance and even appreciation of animal performance training. Again, we need to think 'with Nussbaum against Nussbaum.'

When we turn to performing animals, the balance of care will shift once more, from species-specific care to individual care. Nussbaum argues that both types of care are important for animals to flourish. Her perspective is individualistic in making the living creature - not the group or species - the basic subject of justice, but at the same time she rejects the view that all moral relevance lies in the capacities of the individual. The capabilities approach should give a species-specific account of basic capabilities without losing sight of the capacities and personality of the individual animal. A respectful consideration of the species norm of flourishing should go hand in hand with a respectful attention to the capacities of the individual.

To gain insight in the prospects and problems of individual care for performing animals, including circus animals, it is useful to have a look at the work of two philosophers who have been theoretically and practically engaged in animal training: Donna Haraway and Vicky Hearne (Keulartz and Swart 2012).

Donna Haraway, a path-breaking feminist philosopher, best known for her 1991 essay The Cyborg Manifesto, has more recently been focusing her attention on human-animal relationships. In 2003, she published The Companion Species Manifesto, and in 2008 her book When Species Meet came out. What holds this book together is Haraway's relationship with her Australian shepherd Cayenne, with which she does agility work.

Haraway is less interested in Jeremy Bentham’s famous question “Can animals suffer?” than in the questions: “Can animals play? Or work?” (Haraway 2008, 22) ${ }^{17}$ To better understand and nurture our responsibilities for animals Haraway feels that Karl Marx’s category of labor is more helpful than the Enlightenment's category of rights. According to Haraway, training, working with animals, does not imply submission and oppression; quite the contrary, it requires two-way interaction. Training relies on teamwork; trainer and trainee have to listen to one another if an act or exercise is going to succeed. Here, Haraway refers to the notion of 'isopraxis' used by the French ethologist Jean-Claude Barrey to describe the interaction between horse and rider, where the questions "Who influences and who is influenced?” can receive no clear answer (idem, 229).

Haraway is influenced by the work of Vicky Hearne, an animal trainer, philosopher, and poet, who died in 2001 (see Haraway 2003, 48-54). Hearne, who also put much emphasis

\footnotetext{
${ }^{17}$ Remember that Play is one of the central capabilities on Nussbaum's list.
} 
on mutuality and reciprocity in the working relationships between humans and animals, fiercely opposed the animal rights discourse. In an essay - 'What's Wrong with Animal Rights' - that was included in the 1992 edition of The Best American Essays Series, edited by Susan Sontag, Hearne expressed her fear that animal rights activists, by branding training of any sort as torture, could deprive animals of the satisfaction they experience from work. She disagrees with the definition of 'happiness' as synonym for 'pleasure' and as antonym for 'suffering.' To better understand 'animal happiness' we should trade in Bentham for Aristotle, who considered happiness as activity in accordance with the highest excellence. Happiness is about a sense of personal achievement, like the satisfaction felt by a good woodcarver or a dancer or a poet or an accomplished dressage horse. “This happiness, like the artist's, must come from something within the animal, something trainers call talent, and so cannot be imposed on the animal” (Hearne 1994, 204).

Because Donna Haraway and Vicky Hearne primarily draw on experiences gained from training dogs and horses respectively, one might get the wrong impression that their work is only relevant with regard to domestic animals, not wild animals. However, Haraway explicitly challenges the domestic-wild dichotomy, while Hearne has written extensively and with admiration about trainers who work with wild animals. An example is the essay 'Wittgenstein’s Lion’ about Hubert Wells, well-known for his work with lions for Hollywood movies such as 'Out of Africa'. Another example is her essay 'Can an Ape Tell a Joke' about the acts of Bobby Berosini with his five Orangutans, an essay that was also included in the 1994 edition of The Best American Essays Series.

Hearne was only too well aware that wild animals were under increasing pressure due to ongoing habitat fragmentation and destruction. As a consequence, she writes,

"It looks as though we no longer have the option of simply leaving nature alone, looks as though something more radical is necessary in the way of a transformed relationship with nature than has yet been suggested. Wild-animal training is certainly not a solution to all problems, but the knowledge trainers have may contain clues to imaginative and enlightened ways to take up the burden of responsibility towards animals” (idem, 192).

From the work of Haraway and Hearne, it can be concluded that responsibility for animals in working relations should be considered - to use Haraway's phrase - as 'response-ability' (2008, 88), the ability to listen to animals and to meet their needs. Following Viciane Despret 
(2004), Haraway argues that whether a specific setting is morally acceptable or culpable depends on the animal's possibilities of 'resistance' when its wishes fall on deaf ears and it is forced to compliance and docility. Marine-mammal veterinarian James McBain has formulated this requirement as follows: "We should work with animals as if gates and doors weren't there; as if they could leave any moment they wanted. If they then decide to stay and work with you, then you can say you have a good bond and trust and is the animal truly interested in being with you” (cited in Brando 2010, 783; cf. Brando 2012, 394).

On the one hand, it is obvious that the possibilities for care for the environment in a performance setting are almost absent, while the possibilities for species-specific care are fairly limited. The possibilities for individual care and attention, on the other hand, seem relatively large. One should of course, on a case-by-case basis, try to assess whether the happiness that results from the labor of training and performance can compensate for the lack of care for the environment and the deficit of species-specific care.

Now, Nussbaum seems to be somewhat ambivalent with respect to animal training. On the one hand she is convinced that most domestic animals, such as dogs and horses, have entitlements to ‘suitable education’, Nussbaum's name for training. These animals profit from some training and discipline. Indeed, if they are given the appropriate training they "are capable of fine feats of athletic excellence” (Nussbaum 2006, 377). Nussbaum also seems to suggest that zoo animals are entitled to some forms of training, since she laments that "one of the greatest defects of most zoos has been their boringness, which constitutes a cruel assault on animals’ opportunities for flourishing” (idem, 397). But, on the other hand, Nussbaum seems to be opposed to the use of wild animals in circus acts, as we have seen previously.

However, compared to a zoo environment, a circus environment is likely to address the cognitive abilities of the animals more often, as it may provide more and varied stimuli. That is at least the opinion of Hans Hopster and Ingrid de Jong, the authors of a recent report, commissioned by the Dutch government, that describes the scientific literature and expert views concerning the keeping, training and performance of sea lions in traveling circuses and the consequences for their health and welfare. One of their findings is that according to most experts, sea lion behavior strongly suggests that they are happy to be trained and like to perform. "They express anticipation to performances by looking for the trainer, by waiting at the gate of their accommodation, by willingly entering performance areas and taking their positions (station), by pre-empting clues for behaviors, by walking back and forth, swaying, stretching out to see where the trainers are, and other expressions of eagerness to participate" (Hopster and De Groot 2014, 20). Another finding is that there is a lot of trust between sea 
lions and their trainers, due to the fact that circus trainers literally live with their animals 24 hours a day. "It is therefore highly likely that circus sea lions, besides being economically very valuable for their owners, also have emotional value to them. Within the constraints of the circus, sea lions probably get therefore the best possible care” (ibid.).

It is of course questionable whether the benefits of training and performance for sea lions in traveling circuses outweigh the major hazards to their welfare - the Dutch report mentions pool dimensions, space, social conditions, food and water quality, and exposure to UV light as the major potential causes of poor welfare.

Nussbaum might add that the sea lions' expressions of happiness do not necessarily reflect the truth about their well-being. Their preferences for training and performance could be adaptive preferences - Nussbaum also speaks of ‘submissive' or 'fear-induced' preferences (Nussbaum 2006, 344). ${ }^{18}$ Adaptive preferences are formed under bad or unjust background conditions, as a generally unconscious and unintended adaptation to our actual situation which compares unfavourable with the desired situation. ${ }^{19}$ People under circumstances of poverty, deprivation and injustice can adjust their wants to their possibilities and thus still consider themselves to be happy and well-off - the Happy Slave being the paradigmatic example of this predicament.

We have, however, reason to be very cautious with applying the concept of adaptive preferences to animals. As Nussbaum herself has indicated, “the interpretation of animals' preferences is fraught with obscurity and difficulty” (idem, 343). Recall Nussbaum's example of the tiger in a zoo that appears satisfied when given a large ball on a rope whose resistance and weight symbolize the gazelle. The question is of course whether the tiger is really satisfied or whether he has merely adapted his preferences to his options. The latter is the case if one agrees with Daniel Crescenzo that killing is part of exercising predatory instinct, and that the opportunity to fully exercise predatory instinct is a central capacity in its own right for predators and may thus be essential for predator flourishing. According to Crescenzo, “A large ball on a rope allows for some exercise of the predatory instinct, but the simulation of killing it provides is quite limited” (Crescenzo 2012, 195).

It is obviously very difficult, if not impossible, to distinguish the adaptive from the non-adaptive preferences of animals. More importantly, adapting one’s preferences to ones

\footnotetext{
${ }^{18}$ As Rosa Terlazzo has rightly remarked, Nussbaum's capabilities approach "is centrally motivated by the problem of adaptive preferences" (Terlazzo 2014, 185).

${ }^{19}$ The term 'adaptive preference' was introduced by Jon Elster in his book Sour Grapes from 1983. Elster refers to La Fontaine's (originally Aesop's) fable of the Fox and the Grapes to explain what he means by preference adaptation. In the fable, after realizing that it cannot reach some grapes hanging high on the vine, a hungry fox turns away from them and declares them too sour for its tastes.
} 
situation can be a wise thing to do, a sign of resilience, i.e. the capacity to withstand shocks and surprises, and to maintain or regain psychological well-being in the face of changing and challenging circumstances. It seems at least a wise thing to do for wild animals that have become increasingly dependent on care in conditions of temporary or permanent captivity, as a result of the ongoing blurring of boundaries between in situ and ex situ conservation, and between the wild and the walled.

\section{Concluding Remarks}

Martha Nussbaum certainly deserves credit for breaking with the currently still dominant doctrine of 'moral individualism' that holds that species membership itself is of no ethical and political significance. With the introduction of the species-specific norm of flourishing in the animal ethics debate, Nussbaum has opened up promising avenues towards a morally sound guidance for professionals and practitioners working with wild animals in captivity, which is of imminent importance in the emerging Anthropocene era, the age of human dominion of the Earth, at least if we really want to stop or even reverse the defaunation process. However, to make this avenue accessible and passable, we should abandon Nussbaum's one-fits-all approach, which applies the same human yardstick to all animal species, and develop a truly species-specific account of central animal capabilities.

The task of determining which capabilities members of an animal species typically have is a complex one and calls for a broadening of Nussbaum's methodological perspective. Her conception of flourishing is thoroughly evaluative and ethical (Nussbaum 2006, 366). Nussbaum insists that we cannot simply "read off” species norms directly from observation of animals' characteristic ways of life (idem, 347 and 497). She suggests that we can come to recognize what animal flourishing entails through an Aristotelian-style "considered judgment” in conjunction with 'sympathetic imagination' (idem, 352-53). But, in order to create a really species-specific account of core capabilities, we cannot be content with moral evaluations only but we will have to combine them with empirical investigations from a wide range of animal sciences such as ethology, wildlife ecology, zoo biology, and conservation biology. Some of Nussbaum's statements seem to support such a plea for an empirically informed approach to the evaluation of what is essential to the flourishing of different species. ${ }^{20}$

\footnotetext{
20 "It seems best for humans not to engage in too much second-guessing of animal capabilities, but try to observe what each creature actually considers important, on the basis of what it does... Part of respect for other species is
} 


\section{Literature}

Arnold, W., Ruf, T., Reimoser, S., Tataruch, F., Onderscheka, K., and Schober, F. (2004). 'Nocturnal hypometabolism as an overwintering strategy of red deer (Cervus elaphus),' American Journal of Physiology. Regulatory, Integrative and Comparative Physiology 286,174-181.

Anderson J.R., and Chamove, A.S. (1984). 'Allowing captive primates to forage,' in Standards in laboratory animal management, part 2 (253-257). Hertfordshire, UK: The Universities Federation for Animal Welfare.

Bekoff, M. (2000). 'Redecorating nature: reflections on science, holism, community, humility, reconciliation, spirit, compassion, and love,' Human Ecology Review 7(1), 59-67.

Brando, S. (2010). 'Advances in Husbandry Training in Marine Mammal Care Programs,' International Journal of Comparative Psychology 23, 777-791.

Brando, S. (2012). 'Animal Learning and Training. Implications for Animal Welfare,' Veterinary Clinics: Exotic Animal Practice 15, 387-398.

Bradshaw, E.L., and Bateson, P. (2000). 'Welfare Implications of Culling Red Deer (Cervus Elaphus),' Animal Welfare 9, 3-24.

Claxton, A.M. (2011). 'The potential of the human-animal relationship as an environmental enrichment for the welfare of zoo-housed animals,' Applied Animal Behaviour Science 133, $1-10$.

Cohen, C. (1997). 'Do animals have rights?’ Ethics \& Behavior 7 (2), 91-102.

Coe, J. (2004). 'Mixed species rotation exhibits,' Jon Coe Design Pty Ltd. (originally prepared for ARAZPA 2004 Annual Conference).

Conway, W. (2011). 'Buying time for wild animals with zoos,' Zoo biology 30, 1-8.

Cowen, T. (2003). ‘Policing nature,’ Environmental Ethics 25, 169-182.

Crescenzo, D.L. (2012). 'The Problem of Predator-Prey Relations and Predator Flourishing in Nussbaum’s Capabilities Approach to Justice,' Environmental Ethics 34, 177-197.

Cripps, E. (2010). 'Saving the Polar Bear, Saving the World: Can the Capabilities Approach do Justice to Humans, Animals and Ecosystems,' Res Publica 16: 1-22.

Despret, V. (2004). 'The Body we care for: figures of anthropo-zoo-genesis'. Body \& Society 20 (2-3): 111-134.

Elster, J. (1983). Sour grapes: studies in the subversion of rationality. New York: Cambridge University Press.

a willingness to look and study, learning the internal rhythms of an animal community and the sense of value the way of expresses” (Nussbaum 2006, 371/2). 
European Circus Association (ESA). (2007). Code of conduct for animals.

http://www.europeancircus.info/ECA/index.php?option=com_content\&task=view\&id=83\&It emid=63 (accessed on May 15 2009)

Fa, J.E., Funk, S.M., and O’Connell, D. (2011). Zoo Conservation Biology. Cambridge: Cambridge University Press.

Haraway, D. (2003). The Companion Species Manifesto. Dogs, People, and Significant Otherness. Chicago: Prickly Paradigm Press.

Haraway, D. (2008). When Species Meet. Minneapolis/London: University of Minnesota Press.

Hearne, V. (1992). 'What's Wrong With Animal Rights. Of Hounds, Horses and Jeffersonian happiness,' in: S. Sontag (Eds.) The best American essays. Boston, MA: Houghton Mifflin.

Hearne, V. (1994). Animal Happiness. A Moving Exploration of Animals and Their Emotions. New York: Skyhorse Publishing.

Hediger, H. (1950). Wild Animals in Captivity. London: Butterworths.

Hopcraft, J.G.C., Olff, H., and Sinclair A.R.E. (2009). 'Herbivores, resources and risks: alternating regulation along primary environmental gradients in savannas,' Trends in Ecology and Evolution 25 (2), 119-128.

Hopster, H. and De Jong, I.C. (2014). Welfare of sea lions in travelling circuses. Wageningen UR Livestock Research. Lelystad, The Netherlands, Research Report 770.

Hutchins, M. (2008). ‘Animal rights and Conservation,' Conservation Biology 22 (4), 815816)

Jamieson, D. (1995). 'Zoos revisited,' in B. Norton, M. Hutchins, E. Stevens, and T. Maple (Eds.), Ethics on the Ark (52-66). Washington: Smithsonian Institution Press.

Jamieson, D. (2008). ‘The rights of animals and the demands of nature,' Environmental Values 17, 181-199.

Keulartz, J. (2015). 'Captivity for Conservation? Zoos at a Crossroads,' Journal of Agricultural and Environmental Ethics 28, 335-351

Keulartz, J. (2016). 'Future direction for conservation,’ Environmental Values...

Keulartz, J., and Van der Weele, C. (2008). 'Framing and reframing in invasion biology,' Configurations 16 (1), 93-115.

Keulartz, J., and Swart, J. (2012). 'Animal Flourishing and capabilities in an Era of Global Change,' in A. Thompson and J. Bendik-Keymer (Eds.), Ethical Adaptation to Climate Change (123-144). Cambridge, MA: The MIT Press. 
Klaver, I., Keulartz, J., Van den Belt, H., and Gremmen, B. (2002). 'Born to be Wild: A Pluralistic Ethics Concerning Introduced Large Herbivores in the Netherlands,'

Environmental Ethics 24 (1), 3-23.

Kreger, M. D., Hutchins, M., and Fascione, N. (1998). 'Context, Ethics, and Environmental Enrichement in Zoos and Aquariums,' in D. Shepherdson et al. (Eds.), Second nature.

Environmental Enrichment for Captive Animals (59-82). Washington: Smithsonian Institution Press.

Laule, G., and Desmond, T. (1998). 'Positive reinforcement training as an enrichment strategy,' in D. Shepherdson et al. (Eds.), Second nature. Environmental Enrichment for Captive Animals (302-313). Washington: Smithsonian Institution Press.

McMahan, J. (2010). ‘The Meat Eaters,' The New York Times, September 19, 2010.

Mech, L.D. (2012). 'Is science in danger of sanctifying the wolf?' Biological Conservation 150, 143-149.

Milburn, J. (2015). 'Rabbits, Stoats and the predator problem: why a strong animal rights position need not call for human intervention to protect prey from predators,' Res Publica 21 (3), 273-289.

Miller, B., Dugelby, B., Foreman, D., Marinez del Rio, C., Noss, R., Philips, M., Reading, R., Soulé, M., et al. (2001). 'The Importance of Large Carnivores to Healthy Ecosystems'. Endangered Species UPDATE 18 (5), 202-210.

Minteer, B. A., and Collins, J. P. (2010). 'Move it or lose it? The ecological ethics of relocating species under climate change,’ Ecological Application 20 (7), 1801-1804.

Minteer, B. A., and Collins, J. P. (2013). 'Ecological ethics in captivity: Balancing values and responsibilities in zoo and aquarium research under rapid global change,' ILAR, 54 (1), 4151.

Neuringer, A. (1969). 'Animals respond for food in the presence of free food,' Science 166: 399-401.

Nussbaum, M.C. (2000). Women and Human Development: The Capabilities Approach. Cambridge, UK: Cambridge University Press.

Nussbaum, M.C. (2001). 'Animal rights : the need for a theoretical basis,' Harvard Law Review 114, 1506-49.

Nussbaum, M.C. (2004). 'Beyond the social contract. Toward global justice,' Tanner Lectures on Human Values, volume 24 (413-508). Salt Lake City: University of Utah Press.

Nussbaum, M.C. (2006). Frontiers of Justice. Disability, Nationality, Species Membership. Cambridge, MA: Havard University Press.

Nussbaum, M.C. and Faralli, C. (2007). 'On the New Frontiers of Justice. A Dialogue,' Ratio Juris 20 (2), 145-61. 
Palmer, C. (2010). Animal Ethics in Context. New York: Columbia University Press.

Palmer, C. (2014). 'The Moral Relevance of the Distinction Between Domesticated and Wild Animals,' in T.L. Beauchamp and R.G. Fey (Eds.) The Oxford Handbook of Animal Ethics. New York: Oxford University Press.

Poole, T.B. (1998). 'Meeting a Mammal’s Psychological Needs,' in D.J. Shepherdson, J.D. Mellen and M. Hutchins (Eds.), Second Nature (83-97). Washington: Smithsonian Institute.

Rachels, J. (1990). Created From Animals: The Moral Implications of Darwinism. New York: Oxford University Press.

Regan, T. (1983). The Case for Animal Rights. Berkeley: University of California Press.

Regan, T. (1995). ‘Are zoos morally defensible,' in B. Norton, M. Hutchins, E. Stevens and T. Maple (Eds.), Ethics on the Ark (38-51). Washington: Smithsonian Institute Press.

Ross, S.R. (2002). 'The effect of a simple feeding enrichment strategy on the behaviour of two Asian small-clawed otters (Aonyx cinerea),' Aquatic Mammals 28 (2), 113-120.

Sandler, R.L. (2012). The Ethics of Species. An Introduction. Cambridge, UK: Cambridge University Press.

Schlosberg, D. (2007). Defining Environmental Justice: Theories, Movements, and Nature. New York: Oxford University Press.

Seddon, P.J., Griffiths, C.J., Soorae, P.S., and Armstrong, D.P. (2014). 'Reversing defaunation: Restoring species in a changing world,’ Science 345 (6195), 406-412.

Simmons, A. (2009). 'Animals, predators, the right to life and the duty to save lives,' Ethics and the Environment 14, 15-27.

Singer, P. (1973). 'Food for thought.’ www.nybooks.com. (retrieved 1 July 2015)

Singer, P. (1975). Animal liberation: A new ethics for our treatment of animals, New York: Random House.

Swart, J.A.A. (2005). 'Care for the wild. Dealing with a pluralistic practice,' Environmental Values, 14 (2), 251-263.

Terlazzo, R. (2014). 'The perfectionism of Nussbaum's adaptive preferences,' Journal of Global Ethics 10 (2), 183-198.

Varner, G. (1995). 'Can animal rights activists be environmentalists?' in C. Pierce and D. VanDeVeer (Eds.) People, Penguins, and Plastic Trees, 2d ed. (254-273). Belmont, CA: Wadsworth Publishing Company.

Veasey, J. and Hammer, G. (2010). 'Managing captive mammals in mixed-species communities,' in D.G. Kleiman, K.V. Thompson and C.K. Baer (Eds.) Wild Mammals in 
Captivity. Principles and Techniques for Zoo Management ( $2^{\text {nd }}$ Edition) (151-161). Chicago: The university of Chicago Press.

Wissenburg, M. (2011). 'The lion and the lamb. Ecological implications of Martha Nussbaum’s animal ethics,' Environmental Politics 20, 391-409. 